\title{
Factors associated with recurrent wheezing in the first year of life among premature newborns from Neonatal Intensive Care Units
}

Andréia Caroline Ribeiro Ramos 1

iD https://orcid.org/0000-0001-7850-2340

Patrícia Soares Castro 2

iD https://orcid.org/0000-0002-5364-4737

Rafael Gomes Souza 3

iD https://orcid.org/0000-0002-0532-857X

Jair Almeida Carneiro 4

iD https://orcid.org/0000-0002-9501-918X

\author{
Lucineia de Pinho 5 \\ (iD https://orcid.org/0000-0002-2947-5806 \\ Antônio Prates Caldeira 6 \\ (iD) https://orcid.org/0000-0002-9990-9083
}

1,3,4,5,6 Universidade Estadual de Montes Claros.Av. Dr. Rui Braga, Prédio 6. Campus Universitário Darcy Ribeiro. Montes Claros, MG, Brasil. CEP: $39.401-089$. E-mail: antonio.caldeira@unimontes.br

2 Faculdades Integradas Pitágoras Montes Claros. Montes Claros, MG, Brasil.

\begin{abstract}
Objectives: to determine the prevalence and factors associated with recurrent wheezing in the first year of life among premature newborns from Neonatal Intensive Care Units, in the city of Montes Claros, northern Minas Gerais.

Methods: cross-sectional study, with data collection from medical records of a follow-up clinic, interviews with mothers and, eventually, search in hospital records. Bivariate analyzes were carried out between sociodemographic and clinical characteristics and recurrent wheezing. Variables associated up to the level of $20 \%$ were analyzed by binary logistic regression, and associations defined by the Odds Ratio and respective 95\% confidence intervals. Only variables associated with a 5\% significance level were maintained in the final model of logistic regression.

Results: among 277 infants studied, about one fifth (21.3\%) were extremely low birth weight preterm and more than half (60.7\%) had birth weight below 1500 grams. The prevalence of recurrent wheezing was $14.4 \%(C 195 \%=10.3-18.4)$. Mechanical ventilation $(O R=$ 2.12; $C 195 \%=1.09-4.76 ; p=0.030)$ and oxygen therapy time $\geq 15$ days $(O R=2.49$; $C 195 \%=1.12-5.00 ; p=0.010)$ were the risk factors for the event.

Conclusions: there is a high prevalence of recurrent wheezing in the evaluated group and the associated variables reiterate the risk of prolonged oxygen therapy and mechanical ventilation for premature newborns.
\end{abstract}

Key words Infant, Premature, Respiratory sounds, Prevalence, Risk factors

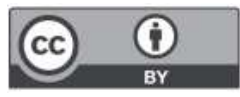




\section{Introduction}

Survival of preterm and low birth weight neonates has been progressively greater with technological advances incorporated into the Neonatal Intensive Care Units (NICU). ${ }^{1}$ However, most of these infants suffer many complications after birth, such as respiratory failure with need for mechanical ventilation, infectious and hemorrhagic conditions and need specialized outpatient follow-up after hospital discharge. ${ }^{2}$ The follow-up of infants discharged from the NICU shows many cases of readmissions, growth and development delays, visual and auditory sequelae and respiratory problems in future life.3-5

The prolonged use of oxygen therapy, with or without mechanical ventilation, the occurrence of neonatal pneumonia and other changes in lung function are examples of factors that make preterm and low birth weight neonates particularly vulnerable to respiratory diseases in the first years of life.6,7 The necessary adaptations to the lung development of premature infants (physiological or not) predispose to the emergence of diseases such as asthma and chronic obstructive pulmonary disease in childhood and adulthood. 7

Bronchopulmonary dysplasia (BPD) represents the main respiratory sequelae for premature infants, presenting with episodes of coughing, wheezing and need for oxygen supplementation, very often evolving with compromised pulmonary function in future life.8-10 However, in addition to BPD, the occurrence of wheezing episodes in the first months of life are widely associated with low gestational age and low birth weight and can also significantly compromise the quality of life of these children. $7,10,11$

In Brazil, there are few studies that investigate the respiratory morbidity of preterm or low birth weight newborns in the first years of life, including, in addition to BPD, pneumonia, hospital admissions for respiratory causes and recurrent wheezing.7,12-14 Considering there is an increase in the survival of very premature infant, it is necessary to increase knowledge about the morbidity profile of this group, in order to provide timely guidance to neonatal care services. In addition to lower respiratory tract infections, recurrent wheezing, defined as the occurrence of three or more episodes of wheezing measured by medical diagnosis in the first year of life, represents an important morbidity to be studied, due to its social and economic impact. 15

Some factors have been shown to be associated with greater respiratory morbidity in the first year of life, especially in premature infants, such as changes or diseases resulting from pulmonary immaturity, ${ }^{16}$ use of mechanical ventilation, ${ }^{13}$ respiratory syncytial virus infection, male gender and low birth weight 17 and prolonged use of oxygen therapy. 9,12 However, there are still few studies that specifically assess the factors associated with recurrent wheezing among preterm infants in the same period.

This study aimed to identify the prevalence and maternal, perinatal, and neonatal factors associated with recurrent wheezing in the first year of life among preterm, high-risk neonates followed up at an outpatient clinic in the north of Minas Gerais State.

\section{Methods}

This is a cross-sectional study conducted from the monitoring of newborns assisted at a high-risk infant follow-up clinic bound to the city's health department in Montes Claros, in the north of Minas Gerais. The city has an estimated population of 410 thousand inhabitants and has only one high-risk infant follow-up clinic, where infants from the two public NICUs are monitored with interdisciplinary assistance. The data were obtained by analyzing the medical records of the infants registered after leaving the NICUs, interviews with their mothers and eventual consults in the hospital records (whenever there weren't medical records available, and the mothers didn't know).

The study included infants registered in the service since 2014, as an attempt to avoid the limitations of older data. For the sample calculation, a prevalence of $17 \%$ of recurrent wheezing episodes in the first year of life was considered, 15 with an error margin of $4 \%$ and confidence level of $95 \%$, which defined a minimum of 264 infants/records to analyze. The inclusion criteria were infants born prematurely (gestational age $<37$ weeks, according to medical record) that had left the NICUs, regularly monitored throughout the first year of life, that is, infants that attended monthly, bimonthly, or quarterly appointments defined by the service. Infants whose mothers did not have precise information about the pregnancy and birth conditions were excluded, as well as those whose most relevant data were not registered in the respective medical records. The flowchart with the process of allocation of the children involved in the study is shown in Figure 1.

Although there is a specific instrument to evaluate recurrent wheezing in infants with family interviews, 18 it wasn't used in the study, since the evaluated group included data that were only researched in previous medical records from infants born 


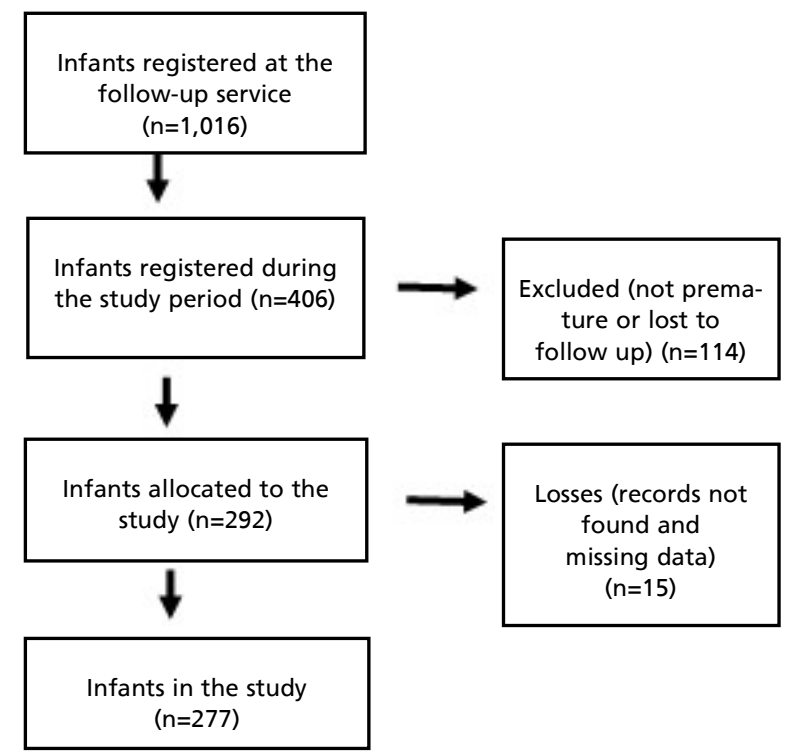

prematurely. The instrument used for collecting data was based on the specific objectives of the study, approaching maternal characteristics, pregnancy and birth conditions and postpartum complications during the NICU stay. Information related to the monitoring of the infants during the first year of life was also collected.

Data collection was performed by two trainee research students, specifically trained to identify data in records and interviews with mothers, and eventually, clarifying information along with the professional team assisting the children. The selection of medical records was performed randomly, by simple random sampling, from the consecutive selection of records, considering for children allocation, the inclusion criterion of complete follow-up in the first year of life. Data collection period was from February to December 2018 and included children assisted between 2014 and 2018 .

The dependent variable was the occurrence of at least three wheezing episodes during the first year of life, registered in the child's chart and/or informed by the mother with a report of inhalatory medication. The independent variables were pregnancy and birth conditions and neonatal complications. Descriptive analysis of data was made by frequency distribution. After bivariate analysis, a binary logistic regression analysis (backward method) was made for evalu- ating all the variables that were associated until the level of $20 \%(p<0.20)$ in the initial analysis. The magnitudes of the associations were defined by the odds ratios and their respective $95 \%$ confidence intervals. For the final model, the significance level was defined by $5 \%$. The adjusting of the multiple final model was made through the HosmerLemeshow test. All the data collected were codified and analyzed through the software IBM-SPSS for Windows version 22.0.

The research project was appreciated and approved by the Research Ethical Committee of the institution where the study was carried out, with a register of CAAE 58699016.8.0000.5146 and approval protocol $\mathrm{n}^{\mathrm{o}} 1.800 .915$.

\section{Results}

Data from 277 infants were collected, with a slight predominance of male sex (54.2\%). Most of mothers had previous deliveries registered $(57.8 \%)$ and the type of birth was predominantly surgical (68.2\%). Gestational records showed that most mothers had complication during pregnancy, and systemic arterial hypertension was the most mentioned (35.7\%). The analysis of the gestational age and birth weight revealed that no more than a fifth of the newborns had extreme low weight and over half the newborns 
weighed less than 1500 grams (Table 1).

Table 2 shows the frequency distribution of the main complications presented by the evaluated group during the NICU stay. Over two thirds of the infants needed oxygen therapy for more than 15 days (66.5\%).

The occurrence of at least three episodes of wheezing (recurrent wheezing) in the first year of life was registered for 40 infants (14.4\%). Table 3 shows the result of the bivariate analysis between the studied characteristics of the group and recurrent wheezing. The variables that were associated up to $20 \%$ level $(p<0,20)$ were analyzed by binary logistic regression.

The variables that, after multiple analysis, have shown association with recurrent wheezing were the use of mechanical ventilation $(p=0.030 ; \mathrm{OR}=2.12$; IC95\% $=1.09-4.76)$ and time of oxygen therapy equal or superior to 15 days $(p=0.010 ; \mathrm{OR}=2.49$; IC95\% $=1.12-5.00)$ (Table 4)

Table 1

Gestational and delivery characteristics of premature neonates followed up in a high-risk follow-up clinic in the north of Minas Gerais; Montes Claros (MG), Brazil; 2014-2018.

\begin{tabular}{|c|c|c|}
\hline Variables & $\mathbf{N}$ & $\%$ \\
\hline \multicolumn{3}{|l|}{ Maternal parity } \\
\hline Primiparous & 127 & 42.2 \\
\hline Multiparous & 150 & 57.8 \\
\hline \multicolumn{3}{|c|}{ Pregnancy complications } \\
\hline Hypertension & 99 & 35.7 \\
\hline Diabetes & 13 & 4.7 \\
\hline Infections & 29 & 10.5 \\
\hline None referred & 112 & 40.4 \\
\hline Others & 24 & 8.7 \\
\hline \multicolumn{3}{|c|}{ Prenatal corticosteroid therapy } \\
\hline Yes & 142 & 51.3 \\
\hline No & 135 & 48.7 \\
\hline \multicolumn{3}{|c|}{ Time of rupture of membranes (hours) } \\
\hline$>18$ & 67 & 24.2 \\
\hline$\leq 18$ & 210 & 75.8 \\
\hline \multicolumn{3}{|l|}{ Childbirth delivery } \\
\hline Natural & 88 & 31.8 \\
\hline Cesarean surgery & 189 & 68.2 \\
\hline \multicolumn{3}{|l|}{ Sex } \\
\hline Male & 150 & 54.2 \\
\hline Female & 127 & 45.8 \\
\hline \multicolumn{3}{|c|}{ Gestational age (weeks) } \\
\hline$<28$ & 31 & 11.2 \\
\hline $28-32$ & 169 & 61.0 \\
\hline$>32$ & 77 & 27.8 \\
\hline \multicolumn{3}{|l|}{ Apgar $5^{\text {th }} \min$} \\
\hline$\geq 7$ & 194 & 70.0 \\
\hline$<7$ & 83 & 30.0 \\
\hline \multicolumn{3}{|l|}{ Birth weight (g) } \\
\hline$<1,000$ & 59 & 21.3 \\
\hline $1,000-1,499$ & 109 & 39.4 \\
\hline$\geq 1,500$ & 109 & 39.4 \\
\hline \multicolumn{3}{|c|}{ Newborn classification* } \\
\hline AGA & 182 & 65.7 \\
\hline SGA & 85 & 30.7 \\
\hline LGA & 10 & 3.6 \\
\hline
\end{tabular}

* $A G A=$ Appropriate for gestational age; $S G A=$ Small for gestational age; $L G A=$ Large for gestational age. 


\section{Discussion}

The results of this study reveal an elevated prevalence of recurrent wheezing among the premature infants that leave NICU throughout their first year of life. However, the prevalence observed was slightly lower than that registered by a large study conducted by Mallol et al.,15 with over 12 thousand infants in various countries in Latin America. Another followup study with moderately premature children (32 to 35 weeks) registered a frequency of $17.8 \%$ of recurrent wheezing reported by parents. 19 The results of a Spanish study revealed a prevalence of $18.8 \%$, also within the gestational age of 32 and 35 weeks. ${ }^{20}$ The

\section{Table 2}

Main complications recorded in the NICU for premature neonates followed up in a high-risk follow-up clinic in the north of Minas Gerais; Montes Claros (MG), Brazil; 2014-2018.

\begin{tabular}{lcc}
\hline Variables & $\mathbf{N}$ & $\%$ \\
\hline Oxygen therapy time (days) & & 22.7 \\
$<7$ & 63 & 10.8 \\
$7-14$ & 30 & 44.8 \\
$15-29$ & 124 & 21.7 \\
$>30$ & 60 & 68.6 \\
Use of vasoactive amines & & 31.4 \\
No & 190 & \\
Yes & 87 & 40.4 \\
Sepsis & & 59.6 \\
No & 112 & \\
Yes & 165 & 65.7 \\
Blood transfusion & & 34.3 \\
No & 182 & 81.6 \\
Yes & 95 & 18.4 \\
Neurological complications & & \\
No & 226 & \\
Yes & 51 & \\
\hline
\end{tabular}

$\mathrm{NICU}=$ Neonatal Intensive Care Unit.

\section{Table 3}

Association between characteristics of the studied group and recurrent wheezing in the first year of life (bivariate analysis) for premature neonates followed up at a high-risk follow-up clinic in the north of Minas Gerais; Montes Claros (MG), Brazil; 2014-2018.

\begin{tabular}{|c|c|c|c|c|c|c|}
\hline \multirow[t]{3}{*}{ Variables } & \multicolumn{4}{|c|}{ Recurrent wheezing } & \multirow[t]{3}{*}{$p$} & \multirow[t]{3}{*}{ OR gross (Cl95\%) } \\
\hline & \multicolumn{2}{|c|}{ Yes } & \multicolumn{2}{|c|}{ No } & & \\
\hline & $\mathrm{n}$ & $\%$ & $\mathrm{n}$ & $\%$ & & \\
\hline Sex & & & & & 0.252 & \\
\hline Female & 15 & 11.8 & 112 & 88.2 & & $0.67(0.34-1.33)$ \\
\hline Male & 25 & 16.7 & 125 & 83.3 & & 1.0 \\
\hline Maternal parity & & & & & 0.067 & \\
\hline Primiparous & 13 & 10.2 & 114 & 89.8 & & $0.52(0.26-1.06)$ \\
\hline Multiparous & 27 & 18.0 & 123 & 82.0 & & 1.0 \\
\hline Prenatal corticosteroid therapy & & & & & 0.607 & \\
\hline No & 21 & 15.6 & 114 & 84.8 & & $1.19(0.61-2.33)$ \\
\hline Yes & 19 & 13.4 & 123 & 86.6 & & 1.0 \\
\hline
\end{tabular}

OR= odds ratio. 
Association between characteristics of the studied group and recurrent wheezing in the first year of life (bivariate analysis) for premature neonates followed up at a high-risk follow-up clinic in the north of Minas Gerais; Montes Claros (MG), Brazil; 2014-2018.

\begin{tabular}{|c|c|c|c|c|c|c|}
\hline \multirow[t]{3}{*}{ Variables } & \multicolumn{4}{|c|}{ Recurrent wheezing } & \multirow[t]{3}{*}{$p$} & \multirow[t]{3}{*}{ OR gross $(\mathrm{Cl} 95 \%)$} \\
\hline & \multicolumn{2}{|c|}{ Yes } & \multicolumn{2}{|c|}{ No } & & \\
\hline & $\mathrm{n}$ & $\%$ & $\mathrm{n}$ & $\%$ & & \\
\hline \multicolumn{3}{|c|}{ Time of rupture of membranes (hours) } & & & 0.788 & \\
\hline$>18$ & 9 & 13.4 & 58 & 86.6 & & $0.89(0.40-1.99)$ \\
\hline$\leq 18$ & 31 & 14.8 & 179 & 85.2 & & 1.0 \\
\hline Childbirth delivery & & & & & 0.227 & \\
\hline Cesarean surgery & 24 & 12.7 & 165 & 87.3 & & $1.23(0.77-3.05)$ \\
\hline Natural & 16 & 18.2 & 72 & 81.8 & & 1.0 \\
\hline Apgar $5^{\text {th }} \min$ & & & & & 0.137 & \\
\hline$<7$ & 8 & 9.6 & 75 & 90.4 & & $0.54(0.24-1.22)$ \\
\hline$\geq 7$ & 32 & 16.5 & 162 & 93.5 & & \\
\hline Resuscitation at birth & & & & & 0.507 & \\
\hline Yes & 21 & 15.9 & 111 & 84.1 & & $1.25(0.64-2.46)$ \\
\hline No & 19 & 13.1 & 126 & 86.9 & & \\
\hline Oxygen therapy time (days) & & & & & 0.019 & \\
\hline$\geq 15$ & 33 & 19.9 & 151 & 82.1 & & $2.68(1.14-6.33)$ \\
\hline$<15$ & 7 & 7.5 & 86 & 92.5 & & 1.0 \\
\hline Mechanical ventilation support & & & & & 0.022 & \\
\hline Yes & 30 & 18.5 & 132 & 81.5 & & $2.39(1.12-5.10)$ \\
\hline No & 10 & 8.7 & 105 & 91.3 & & 1.0 \\
\hline Birth weight $(g))$ & & & & & 0.259 & \\
\hline$<1,000$ & 12 & 20.3 & 47 & 79.7 & & $1.48(0.65-3.39)$ \\
\hline $1,000 \mathrm{~g}-1,499$ & 12 & 11.0 & 97 & 89.0 & & $0.72(0.32-1.60)$ \\
\hline$\geq 1,500$ & 16 & 14.7 & 93 & 85.3 & & 1.0 \\
\hline Gestational age (weeks) & & & & & 0.048 & \\
\hline$<28$ & 9 & 29.0 & 22 & 71.0 & & $3.09(1.09-8.76)$ \\
\hline $28-32$ & 22 & 13.0 & 147 & 87.0 & & $1.13(0.49-2.59)$ \\
\hline$>32$ & 9 & 11.7 & 68 & 88.3 & & 1.0 \\
\hline Use of vasoactive amines & & & & & 0.102 & \\
\hline Yes & 17 & 19.5 & 70 & 80.5 & & $1.76(0.89-3.50)$ \\
\hline No & 23 & 12.1 & 167 & 87.9 & & 1.0 \\
\hline Blood transfusion & & & & & 0.024 & \\
\hline Yes & 20 & 21.1 & 75 & 78.9 & & $2.16(1.10-4.25)$ \\
\hline No & 20 & 11.0 & 162 & 89.0 & & 1.0 \\
\hline Sepsis & & & & & 0.449 & \\
\hline Yes & 26 & 15.8 & 139 & 84.2 & & $1.31(0.65-2.64)$ \\
\hline No & 14 & 12.5 & 98 & 87.5 & & 1.0 \\
\hline
\end{tabular}

OR= odds ratio.

variability of the results between the studies can be justified by differences in the evaluated public, considering the inclusion or not of premature infants, the degree of prematurity of the group and the number of episodes that define the recurrent wheezing.

There are few studies in Brazil that approach respiratory morbidity in premature infants, although several authors highlight the relevance of the subject and approach related subjects in their works. 10,1214,16 In a study with premature infants that had been in a NICU during the first year of life, the authors registered a prevalence of $27.8 \%$ of airway obstructive syndrome, which was defined by the presence of recurrent wheezing (two or more episodes of wheezes that cause shortness of breath, fatigue or 
Variables associated with recurrent wheezing in the first year of life (binary logistic regression) for premature neonates followed up at a high-risk follow-up clinic in the north of Minas Gerais; Montes Claros (MG), Brazil; 20142018.

\begin{tabular}{|c|c|c|}
\hline Variables & $p$ & OR adjusted ( $\mathrm{Cl} 95 \%)$ \\
\hline Maternal parity & 0.079 & \\
\hline Primiparous & & $0.47(0.20-1.09)$ \\
\hline Multiparous & & 1.0 \\
\hline Apgar $5^{\text {th }} \min$ & 0.067 & \\
\hline$<7$ & & $0.45(0.19-1.17)$ \\
\hline \multicolumn{3}{|l|}{$\geq 7$} \\
\hline Oxygen therapy time (days) & 0.010 & \\
\hline$\geq 15$ & & $2.49(1.12-5.00)$ \\
\hline$<15$ & & 1.0 \\
\hline Mechanical ventilation support & 0.030 & \\
\hline Sim & & $2.12(1.09-4.76)$ \\
\hline No & & 1.0 \\
\hline Gestational age (weeks) & 0.138 & \\
\hline$<28$ & & $1.96(0.81-4.75)$ \\
\hline $28-32$ & & $1.02(0.88-2.20)$ \\
\hline$>32$ & & 1.0 \\
\hline Use of vasoactive amines & 0.463 & \\
\hline Yes & & $1.32(0.59-2.97)$ \\
\hline No & & 1.0 \\
\hline Blood transfusion & 0.231 & \\
\hline Yes & & $1.66(0.72-3.80)$ \\
\hline No & & 1.0 \\
\hline
\end{tabular}

OR= odds ratio.

Hosmer e Lemeshow test: $p=0.119$.

respiratory difficulties). ${ }^{12}$ In this case, the high prevalence can be attributed to the concept assumed for recurrent wheezing. In a more recent study, the authors registered a prevalence of $27.4 \%$ for recurrent wheezing in a year, but though the study included only infants born prematurely, it was not restricted to the first year of life. 14

Another national study made in five Brazilian capitals revealed a much bigger prevalence of recurrent wheezing among low birth weight newborns, which reached $28 \% .6$ The circumstances of data collection, however, limit the possibility of comparison with the results of this research, since the referred study was made throughout five years, using only interviews with mothers, without a medical diagnosis confirmation and the analysis restricted to low-birth-weight neonates, which does not define prematurity.

Scientific literature registers an unequivocal association between prematurity and the development of future pulmonary diseases during childhood, regardless of bronchopulmonary dysplasia occur- rence. $7,21,22$ To Friedrich et al.,16 both prematurity itself, as well as the interventions and care necessary to maintain the life of preterm infants, apparently alter permanently, to a greater or lesser degree, the development of the respiratory system. Other authors also register the association between prematurity and bronchial hyperresponsivity. 23

The association between prematurity and wheezing is robust, to different studies, even when the concepts of prematurity (different gestational ages) and asthma (medical diagnosis, family, recurrent wheezing) are adjusted. 24 The precise mechanisms that would explain the association between prematurity and recurrent wheezing or asthma are still not well understood. In a large study including a systematic revision and meta-analysis that approached the association between prematurity and asthma, the authors concluded that neither a persistent reduced volume in the airways of infants born prematurely, nor the presence of inflammatory cytokines in their airways, nor an eventually faster growth could explain the association consistently. 
The authors suggest further studies to improve the knowledge basis of development adaptations in premature lungs. 25

In summary, the conclusions of the most robust studies highlight that the association between wheezing in the future life (after the first year of life) and premature birth can be related to the care provided to the newborn. 24,25 In the analysis of factors associated to recurrent wheezing in this study, which included only infants born prematurely, two variables remained related after multiple analysis and both were associated with the use of resources for respiratory supplementation: the period of oxygen therapy being equal or superior to 15 days and the use of mechanical ventilation.

Regarding the damages associated with the prolonged use of oxygen therapy in the neonatal period, there is already a well-consolidated association with bronchopulmonary dysplasia (BPD). Some studies including animal models have already identified that exposure to high concentrations of oxygen by itself can induce inflammation, fibrosis, and emphysema in immature lungs.26,27 For some authors, the abusive use of oxygen tends to cause a larger production of reactive oxygen species, leading to a higher susceptibility to oxidative stress and cellular damage in the alveoli of the immature lung. 27,28

The association between respiratory diseases and mechanical ventilation has already been previously registered by researchers who evaluated neonatal risk factors for respiratory morbidity in the first year of life in premature newborns. ${ }^{13}$ However, the study did not evaluate in a distinct way the recurrent wheezing in the first year of life. Some authors point that the use of mechanical ventilation, even for short periods, is sufficient to induce the release of proinflammatory cytokines in the newborns' premature lungs, leading to injuries that can be harmful in the future, and recommend alternative means of protection other than conventional mechanical ventilation. 29

It is known that the positive pressure and the excessive volume administrated through assisted ventilation can cause damage to immature lung from exacerbated inflation of the alveoli, causing cellular damage and inflammation, regardless of the toxicity associated to oxygen therapy. 9 A recent study done with sheep concluded that there are specific patterns of injuries for a given gestational age, in response to the same mechanical ventilation strategy. The authors conclude that the results found reinforce the need to develop individual respiratory support approaches, specific to the gestational age of the premature infant. 30

Blanken et al. 19 carried out a large research on risk factors for wheezing in the first year of life of premature infants, but it was restricted to gestational age from 32 to 35 weeks. In bivariate analysis, the authors reported an association with mothers that smoked and had a history of atopy, male sex infants, ventilatory support in the neonatal period and other variables related to health assistance in the first year of life. Nonetheless, after multivariate analysis, the authors concluded that, for the evaluated group (moderately premature infants), the lack of assistance in childcare was the variable that presented the highest populational risk attributable to recurrent wheezing.

Few national studies evaluate in specific way the respiratory conditions in follow-up of premature infants. In a recent study made with a similar approach, which analyzed infants from three to four years old, the authors concluded that a history of atopy, shorter gestational age and coexistence with two or more children presented a significant association with recurrent wheezing. The authors also reported that infants with a shorter gestational age which received monoclonal antibodies against the respiratory syncytial virus had a higher prevalence of recurrent wheezing than the group of infants with a larger gestational age. 14 In the referred study, the authors did not evaluate the environmental factors during the neonatal period, highlighting mostly post neonatal risk factors associated to recurrent wheezing in infants, which was made in a reduced version in another study. 18

The results of this study should be analyzed considering some limitations: the emphasis of the analysis was for variables related to the conditions of birth and neonatal period, but variables such as the use of surfactants or maximum intensity of mechanical ventilation parameters were not studied. We also did not evaluate socioeconomic factors, use of monoclonal antibodies against the respiratory syncytial virus, family history of asthma, access to health services after discharge from the NICU or clinical conditions associated, such as gastroesophageal reflux, which is relatively common in the population studied. There are other limitations related to the generalization of the data (external validation), considering that the infants evaluated had been to NICU, therefore had a specific profile of prematurity and conditions of survival during the neonatal period. Regardless of the need for other national studies on the subject, the results are relevant and highlight the necessity of a greater vigilance on the use of ventilatory support for premature 
newborns.

The results of the present study reinforce the risks of prolonged oxygen therapy and mechanical ventilation in premature neonates, which are related to the development of recurrent wheezing. The authors recommend further studies considering the limitations identified and alert that the success in the care of premature and low weight neonates canno be based only in their survival, but in their quality of life and future costs for the family and society.

\section{Acknowledgments}

The authors are grateful for the financial support of this research by Fundação de Apoio à Pesquisa do Estado de Minas Gerais - FAPEMIG (APQ-0203015) and Conselho Nacional de Desenvolvimento Científico e Tecnológico - CNPq (research productivity grant).

\section{References}

1. Glass HC, Costarino AT, Stayer SA, Brett CM, Cladis F, Davis PJ. Outcomes for extremely premature infants. Anesth Analg. 2015; 120 (6): 1337-51.

2. Natarajan G, Shankaran S. Short and long term outcomes of moderate and late preterm infants. Am J Perinatol. 2016; 33: 305-17.

3. Hannan KE, Hwang SS, Bourque SL. Readmissions among NICU graduates: who, when and why? Semin Perinatol. 2020; 44: 151245 .

4. Skromme K, Vollsaeter M, Oymar K, Halvorsen T. Respiratory morbidity through the first decade of life in a national cohort of children born extremely preterm. BMC Pediatr. 2018; 18: 102.

5. Silva LV, Araújo LB, Azevedo VMGO. Avaliação do desenvolvimento neuropsicomotor de lactentes nascidos prematuros com e sem displasia broncopulmonar no primeiro ano de vida. Rev Bras Ter Intensiva. 2018; 30 (2): $174-80$.

6. Aranda CS, Wandalsen GF, Mallol J, Solé D. Brazilian EISL Group. Wheezing and low birth weight. Pediatr Allergy Immunol. 2015; 26: 82-5.

7. Fierro JL, Passarella M, Lorch SA. Prematurity as an Independent Risk Factor for the Development of Pulmonary Disease. J Pediatr. 2019; 213: 110-4.

8. Tapia JL, Agost D, Alegria A, Standen J, Escobar M, Grandi C, et al. Displasia broncopulmonar: incidência, fatores de risco e utilização de recursos em uma população sul-americana de recém-nascidos de muito baixo peso. J. Pediatr (Rio J.) 2006; 82 (1): 15-20.

9. Davidson LM, Berkelhamer SK. Bronchopulmonary Dysplasia: Chronic Lung Disease of Infancy and LongTerm Pulmonary Outcomes. J Clin Med. 2017; 6 (1): E4.

10. Gonçalves C, Wandalsenb G, Lanzab F, Goulart AL, Solé

\section{Authors' contribution}

Caldeira AP, Pinho L, Carneiro JA: idea conception, data analysis, project management, original manuscript draft, and final writing review. Ramos ACR, Souza RG: data collection, data analysis, and final draft review. All authors approved the final version of the article.

D, Santos A. Repercussions of preterm birth on symptoms of asthma, allergic diseases and pulmonary function, 6-14 years later. Allergol Immunopathol (Madr). 2016; 44 (6): 489-96.

11. Duijts L. Fetal and infant origins of asthma. Eur J Epidemiol. 2012; 27: 5-14.

12. Mello RR, Dutra MV, Lopes JM. Morbidade respiratória no primeiro ano de vida de prematuros egressos de uma unidade pública de tratamento intensivo neonatal. J Pediatr (Rio J.). 2004; 80: 503-10

13. Mello RR, Dutra MVP, Ramos JRM, Boechat MC, Daltro $\mathrm{P}$, Lopes JMA. Neonatal risk factors for respiratory morbidity in the first year of life among premature infants. São Paulo Med J. 2006; 124: 77-84.

14. Simões MC, Inoue Y, Matsunaga NY, Carvalho MR, Ribeiro GL, Morais EO, Ribeiro MAGO, Morcillo AM, Ribeiro JD, Toro AADC. Recurrent wheezing in preterm infants: Prevalence and risk factors. J Pediatr (Rio J). 2019; 95: 720-7.

15. Mallol J, Solé D, Garcia-Marcos L, Rosario N, Aguirre V, Chong H, Urrutia-Pereira M, Szulman G, Niederbacher J, Arruda-Chaves E, Toledo E, Sánchez L, Pinchak C, EISL Latin American Group. Prevalence, Severity, and Treatment of Recurrent Wheezing During the First Year of Life: A Cross-Sectional Study of 12,405 Latin American Infants. Allergy Asthma Immunol Res. 2016; 8 (1): 22-31.

16. Friedrich L, Corso AL, Jones MH. Prognóstico pulmonar em prematuros. J Pediatr (Rio J.) 2005; 81 (1): S79-S88

17. Fauroux B, Gouyon JB, Roze JC, Guillermet-Fromentin C, Glorieux I, Adamon L et al. Respiratory morbidity of preterm infants of less than 33 weeks gestation without bronchopulmonary dysplasia: a 12-month follow-up of the CASTOR study cohort. Epidemiol Infect. 2014; 142: 136274 
18. Dela Bianca AC, Wandalsen GF, Miyagi K, Camargo L, Cezarin D, Mallol J, Solé D. International study of wheezing in infants (IESL): validation of written questionnaire for children aged below 3 years. J Investig Allergol Clin Immunol. 2009; 19 (1): 35-42.

19. Blanken OM, Korsten K, Tamminga S, Nibbelke EE, Sanders EAM, Smit HA, Groenwold RH, Bont L, Dutch RSV Neonatal Network. Population-Attributable Risk of Risk Factors for Recurrent Wheezing in Moderate Preterm Infants During the First Year of Life. Paediatr Perinat Epidemiol. 2016; 30 (4): 376-85.

20. Pérez-Yarza EG, Moreno-Galdó A, Ramilo O, Rubí T Escribano A, Torres A, Sardón O, Oliva C, Pérez G, Cortell I, Rovira-Amigo S, Pastor-Vivero MD, Pérez-Frías J, Velasco V, Torres-Borrego J, Figuerola J, Barrio MI, García-Hernández G, Mejías A. Risk factors for bronchiolitis, recurrent wheezing, and related hospitalization in preterm infants during the first year of life. Pediatr Allergy Immunol. 2015; 26 (8): 797-804.

21. Stoll BJ, Hansen NI, Bell EF, Walsh M, Carlo WA, Shakaran S, Lapook AR, Sánchesz PJ, Van Meurs KP, Wyckoff M, Das A, Halle CE, Ball MB, Newman NS, Schibler K, Poindexter BB, Kennedy KA, Cotten CM, D'Angio CT, DeMauro SB, Truoq WE, Devaskar U, Higgings R, Shriver EK, Eunice Kennedy Shriver, National Institute of child health and human development neonatal research network. trends in care practices, morbidity, and mortality of extremely preterm neonates, 1993-2012. JAMA. 2015; 314: 1039-51.

22. Been JV, Lugtenberg MJ, Smets E, van Schayck CP, Kramer BW, Mommers M, Sheikh A. Preterm Birth and Childhood Wheezing Disorders: A Systematic Review and Meta-Analysis. PLoS Med. 2014; 11 (1): e1001596.

23. Clemm HH, Engeseth M, Vollsaeter M, Kotecha S, Halvorsen T. Bronchial hyper-responsiveness after preterm birth. Paediatr Respir Rev. 2018; 34-40.
24. He H, Butz A, Keet CA, Minkovitz CS, Hong X, Caruso DM, Pearson C, Cohen RT, Wills-Karo M, Zuckerman BS, Hughes ME, Wang X. Preterm Birth with Childhood Asthma: The Role of Degree of Prematurity and Asthma Definitions. Am J Respir Crit Care Med. 2015; 192 (4): 520-3.

25. Sonnenschein-Van der Voort AMM, Arends LR, Jongste JC, Annesi-Maesano I, Arshad SH, Barros H. Preterm birth, infant weight gain, and childhood asthma risk: A metaanalysis of 147,000 European children. J Allergy Clin Immunol. 2014; 133 (5): 1317-29.

26. Jobe AH, Kallapur SG. Long term consequences of oxygen therapy in the neonatal period. Semin Fetal Neonatal Med. 2010; 15 (4): 230-5.

27. Ambalavanan N, Morty RE. Searching for better animal models of BPD: A perspective. Am J Physiol Lung Cell Mol Physiol. 2016; 311 (5): L924-27.

28. Vento M, Moro M, Escrig R, Arruza L, Villar G, Izquierdo I, Roberts LJ, Arduini A, Escobar JJ, Sastre J, Asensi MA. Preterm resuscitation with low oxygen causes less oxidative stress, inflammation, and chronic lung disease. Pediatrics. 2009; 124: e439-e449.

29. Carvalho CG, Silveira RC, Procianoy RS. Ventilatorinduced lung injury in preterm infants. Rev Bras Ter Intensiva. 2013; 25: 319-26.

30. Oakley RB, Tingay DG, McCall KE, Perkins EJ, Sourial M, Dargaville PA and Pereira-Fantini PM. Gestational Age Influences the Early Microarchitectural Changes in Response to Mechanical Ventilation in the Preterm Lamb Lung. Front Pediatr. 2019; 7: 325.

Received on February 26, 2020

Final version presented on June 21, 2021

Approved on July 19, 2021 